\title{
Proceeding
}

Supplementary Issue: Autumn Conferences of Sports Science. Costa Blanca Sports Science Events, 18-19 December 2020. Alicante, Spain.

\section{The positive impact of physical activity on working memory abilities: Evidence from a large Italian pre- adolescent sample}

\author{
GABRIELE RUSSO ${ }^{1} \triangleleft$, GIOVANNI OTTOBONI ${ }^{2}$, ALESSIA TESSARI ${ }^{2}$, ANDREA CECILIANI ${ }^{1}$ \\ ${ }^{1}$ Department for Life Quality Studies, University of Bologna, Italy \\ ${ }^{2}$ Department of Psychology, University of Bologna, Italy
}

\begin{abstract}
Physical activity (PA) is an essential component of people's well-being. Copious evidence argues for its protective effect across individuals' lifespan. However, its role as a factor of enhancement for human cognitive skills is still a matter of study. The present work aims to provide conclusive evidence about PA's role in modulating working memory skills in active pre-adolescent children. By enrolling a large number of participants, we tested the effect of PA on Digit Span Backwards (DSB), a well-consolidated test taxing primarily short-term auditory memory, i.e., less dependent on attention fluctuations. Higher working memory capacity was assumed to emerge in the participants practising PA compared to the less active ones. Moreover, due to the different activities participants reported to practice, we expected that children practising open-skill activities manifested better memory skills than the peers practising closed-skill activities, due to the intrinsic nature of the two forms of exercises. Data supported the previous hypothesis highlighting PA's positive effect; however, they did not keep the assumed differences for open vs closed skills. Results are discussed in the light of the cognitive efforts required to sport beginners, particularly in the light of what they are prompted to code, remember and recall in each step of the proposed exercises.
\end{abstract}

Keywords: Cognitive function; Physical exercise; Sports activity; Schoolchildren.

Cite this article as:

Russo, G., Ottoboni, G., Tessari, A., \& Ceciliani, A. (2021). The positive impact of physical activity on working memory abilities: Evidence from a large Italian pre-adolescent sample. Journal of Human Sport and Exercise, 16(2proc), S277-S288. doi:https://doi.org/10.14198/ihse.2021.16.Proc2.13

Corresponding author. Department for Life Quality Studies, University of Bologna, C.so D’Augusto 237, 47921, Rimini, Italy. https://orcid.org/0000-0002-7779-6225

E-mail: russo.gabriele@gmail.com

Abstract submitted to: Autumn Conferences of Sports Science. Costa Blanca Sports Science Events, 18-19 December 2020. Alicante, Spain.

JOURNAL OF HUMAN SPORT \& EXERCISE ISSN 1988-5202

(c) Faculty of Education. University of Alicante

doi:10.14198/jhse.2021.16.Proc2.13 


\section{INTRODUCTION}

Physical activity $(\mathrm{PA})$ is an essential component of people's well-being. It is generally described as "any bodily movement produced by skeletal muscle that requires energy expenditure" (Caspersen, Powell, Christenson, 1985). When PA is null, rare, or even thwarted- as it has happened during the COVID-19 lockdown (Qinf, Song, Yiqing, Nassis, Zhao, Cui et al., 2020, Raiola, Aliberti, Esposito, Altavilla, D'Isanto, D'Elia, 2020; Who, 2020), it impacts negatively on most of the physiological and the psychological functions (Elward \& Larson, 1992; Harridge \& Lazarus, 2017; Paluska \& Schwenk, 2000; WHO, 2018).

PA is a crucial protecting factor across individuals' lifespan (Altavilla, D'Elia, Raiola, 2018; Raiola, 2015). In adulthood, it facilitates oxygen saturation and glucose delivery (Barnes and Corkery, 2018) by working on cardio-physiological functioning (Zhu et al. 2015), to the extent to delay cognitive decline in advanced adulthood (Panza, Taylor, MacDonald, Johnson, Zaleski, Livingston et al. 2008). In childhood, PA and sports exercise practice increase cognitive functions (Biddle \& Asare, 2011; Biddle, Stuart, Ciaccioni, Thomas \& Vergeer, 2019; de Bruijn. Kostons, Van der Fels, Visscher, Oosterlaan, Hartman \& Bosker, 2019; de Greef, Bosker, Oosterlaan, Visscher, Hartman, 2019; Donnelly, Hillman, Castelli, Etnier, Lee, Tomporowski, Lambourne, \& Szabo-Reed, 2016; Marsico, Isanto, Raiola \& Cassese, 2019; O'Brien, Ottoboni, Tessari, Setti, 2017; 2020; Russo, Nigro, Raiola \& Ceciliani, 2019). Tomporowski and colleagues (2008) summarized evidence reporting PA to ameliorate executive functions such as intelligence. Sibley and Etnier (2003) highlighted a positive relation between PA and both perceptual skills and intelligence, but no increment was observed at the level of memory skills. Similar results were also found in a recent study in which participants who were involved in extra-physical activity program had higher self-esteem, but not higher memory skills study (Russo, Nigro, Raiola, \& Ceciliani, 2019). However, another recent systematic review analysis (64 investigations) showed that PA is positively related to both attentional and memory functions (Donnelly et al., 2016). Furthermore, recent findings reported better working memory abilities in physically active children when compared to less active ones (de Greef et al., 2019; Fairclough, Beighle, Erwin \& Ridgers, 2012; Hsieh, Tsai, Chang, Huang \& Hung, 2018; Scudder, Drollette, SzaboReed, Lambourne, Fenton, Donnelly \& Hillman, 2016).

On the other hand, other evidence suggested controversial correlations between PA and cognitive functions. For instance, Keely and Fox (2009) reviewed 18 studies to assess whether physical activity and fitness could improve either academic achievement, learning and cognitive function. The reviewed studies showed consistent, although, moderate positive correlations for what concerns the correlations between PA and academic achievement. Differently, the PA emerged to have a positive effect on executive control function (Buck, Hillmann \& Castelli, 2007), while a small impact on the cognitive assessment system (CAS) test outcomes (Davis, Tomporowski, Boyle, Waller, Miller, Naglieri \& Gregoski, 2007). Another longitudinal research, which involved a large sample of children aged 6 and 13 (Sjowall, Hertz \& Klingberg, 2017), did not report any positive effect of PA on working memory. Additionally, another recent investigation (Russo, Castagnoli, Babini \& Ceciliani, 2020) said that physical activity affected attention but not on working memory capacity.

PA impact on cognitive function has been generally studied independently of the nature of the type of exercises. However, PA and sports activities can be sorted according to the amount of volatility they impose on each athlete to achieve the goal while carrying out a muscular exercise. The physical and sports activities that are performed in a changing environment are defined as open skills activities. During these activities, athletes adapt themselves to the mutable situations of the environment, store as much information as possible and recall it on demand (Furley \& Memmert, 2010; Ottoboni, Russo \& Tessari, 
2015; Tessari, Ottoboni \& Nicoletti, 2013). Examples of open-skill sports are football, basketball and tennis. Conversely, running, and cycling are examples of activities where people are performed in more stable environments than before. For this reason, such sports are defined as closed-skill activities (Schmidt \& Wrisberg, 2008; Russo \& Ottoboni, 2019).

In light of the different natures of the two types of activity, one could assume that some cognitive functions are modulated more than others. A very recent systematic review confirmed the previous assumption highlighting better visual attention, higher problem-solving abilities, and more function inhibitory control in people used to perform open-skill activities than in people used to practice closed-skills sports (Gu, Zou, Loprinzi, Quan \& Huang, 2019). However, the review results come from a heterogeneous background: the studies considered enrolled participants of different ages, samples of varying numerosity, and different methodologies. Due to the evidence suggesting different cognitive development, the enrolment of participants ageing from 9.6 to 70.5 years old might lead to spurious effects (Kwon, Reiss \& Menon, 2002). In the same manner, considering studies from 20 to 660 participants (Mean $=97, S D=140$ ) might confound the final reports. Finally, the variability of the tests adopted delayed the statement of definitive conclusions (Donnelly et al., 2016; Keely \& Fox, 2000).

\begin{abstract}
Aim
Aiming at filling such gaps, we enrolled a large group of participants of closed age. We assessed a cognitive ability, i.e., the working memory, through the Digit Span Backwards (DSB), a well-consolidated test usually adopted in developmental and educational studies (Gathercole \& Alloway, 2006, Rosental et al., 2006). When compared to Digit Span Forwards (DSF), DSB is assumed both to rely on the maintenance of information into the "phonological loop" and to require vigorous executive control to code, translate and manipulate the reverse digit sequence (Hale et al., 2002; Reynolds,1997). Simultaneously, DSF relies on attention less than DSB (Yang, Jutagir, Koyama, Craddock \& Yean, 2015). Moreover, DSB is involved in visual-spatial skills (St Clair-Thompson \& Allen, 2013). Thus, the ability to manipulate information while in temporary storage may represent the assessment of choice in disentangling the effects carried out by open and closed skill sports (Gu et al., 2019).
\end{abstract}

While enrolling participants, we respected the different components of physical activities. Their performance was compared to a control group of the same age who regularly did not practice physical or sports activity.

\title{
Hypothesis
}

We hypothesized to yield higher working memory (WM) outcomes from the participants used to practice PA compared to the less active ones. Moreover, in physically active participants, we hypothesized higher WM outcomes in students practising open skills activities than closed skills ones.

As it is well established that WM capacities improve throughout childhood and adolescence into adulthood, due to increment of brain activation in the right and left dorsoventral prefrontal cortex, the left and right posterior parietal cortex, as well as in left premotor cortex (Kwon, Reiss \& Menon, 2002), we controlled the confounding effect of the factor Age by standardizing the WM data according to the Italian Neuropsychological Evaluation Battery for Adolescents (Gugliotta, 2009). No gender differences in performance were hypothesized (Hill, Laird \& Robinson, 2014; Hyde, 2016). 


\section{METHODS}

\section{Ethical approval}

In October 2019, the study was approved both by the ethical committee of Rimini municipality and by the School council governing the secondary schools involved in the research.

\section{Participants}

One-hundred and ten students (63 females) from several secondary schools of Rimini (Italy) were recruited. They were on average 12.56 years old $(S D=0.58)$.

When children reported practising sports such as basketball, tennis, and football at least two days per week, they were included in the Physically Active - Open Skill group (PAO); when they reported practising track-field, swimming, and rhythmic gymnastics for at least two days per week, they were included in the Physically Active - Closed Skill group (PAC); when they reported not to practice any physical activities regularly, they were included in the Control group (C).

Fifty (18 females) pre-adolescents belonged to the PAO; 25 (22 females) belonged to PAC; 35 (23 females) composed the $\mathrm{C}$.

Overall, the PAO group has 3.18 sessions per week (SE $=0.15)$, the PAC group had 2.76 sessions (SE = 0.23 ) and the $C$ one $0.20(S E=0.07)$ sessions $(F(2,107)=116.66, p<.001)$. Post-hoc analysis with Bonferroni correction revealed significant differences between the PAO group and the $\mathrm{C}$ one $(\mathrm{t}(107)=$ $14.78, p<.001)$ and between the PAC group and the $C$ one $(t(107)=10.69, p<.001)$. No-differences between the PAO group and PAC one $(t(107)=1.87, p<.19)$ were found.

Table 1. Distribution of participants per sport together with the averaged distribution of times per sport per week.

\begin{tabular}{llcc}
\hline Group & Activity & Number of beginners & Number of times of practice per week \\
\hline PAC & Track-field & 1 & 2 \\
& Swimming & 6 & $\mathrm{M}=3.14, \mathrm{SD}=1.35$ \\
& Rhythmic gymnastics & 3 & $\mathrm{M}=2.87, \mathrm{SD}=1.15$ \\
& Triathlon & 1 & 5 \\
& CrossFit & 1 & 2 \\
& Dancing & 10 & $\mathrm{M}=2.9, \mathrm{SD}=1.29$ \\
& Horse riding & 1 & 2 \\
& Skating & 2 & $\mathrm{M}=2, \mathrm{SD}=0$ \\
\hline PAO & Basketball & 6 & $\mathrm{M}=3.5, \mathrm{SD}=1.38$ \\
& Baseball & 1 & 5 \\
& Football & 17 & $\mathrm{M}=3.29, \mathrm{SD}=0.92$ \\
& Martial Arts & 13 & $\mathrm{M}=3.17 . \mathrm{SD}=1.03$ \\
& Frisbee & 3 & $\mathrm{M}=3.3, \mathrm{SD}=1.53$ \\
& Volleyball & 4 & $\mathrm{M}=4, \mathrm{SD}=0$ \\
& Tennis & 6 & $\mathrm{M}=2.3, \mathrm{SD}=0.82$ \\
\hline
\end{tabular}

${ }^{*}$ Martial Arts refer to judo, karate, kung-fu and boxing. 


\section{Procedure}

After collecting Gender and Age information, each participant performed the Auditory Digit Span Backwards. The task required participants to memorize a sequence of digits, which were presented verbally. Each digit was spelt within one second, while the inter-interval pause between two consecutive digits was of one second. The number of digits was incremental and started from a sequence of two. After each sequence, participants were required to recall the digits in the reserve order to the presented one. If the participant was unable to remember the given sequence, a second digit sequence of the same length was provided. If the participant failed again to remember the second sequence, the test was interrupted, and the last remembered digit sequence length was scored as memory span.

\section{Data analyses}

An ANOVA was run through R Software (https://rstudio.com/, RStudio Inc. v. 1.2.5033).

The dependent variable was the length of the last correctly remembered digit sequence. The independent variables were Physical Activity ( 3 levels, PAO, PAC and C), and Gender ( 2 levels). All the variables were between-subjects' factors. When necessary for multiple comparisons, post-hoc analysis with Bonferroni correction was performed.

Z-scores (Equation 1) were calculated by setting the mean and the standard deviation evidenced in the test validation work for the Italian population (Gugliotta, 2009), corrected for each participant's age.

$$
Z=\frac{\text { WM students }- \text { Mean WM population per Age }}{S D \text { population per Age }} \text { (Equation 1) }
$$

\section{RESULTS}

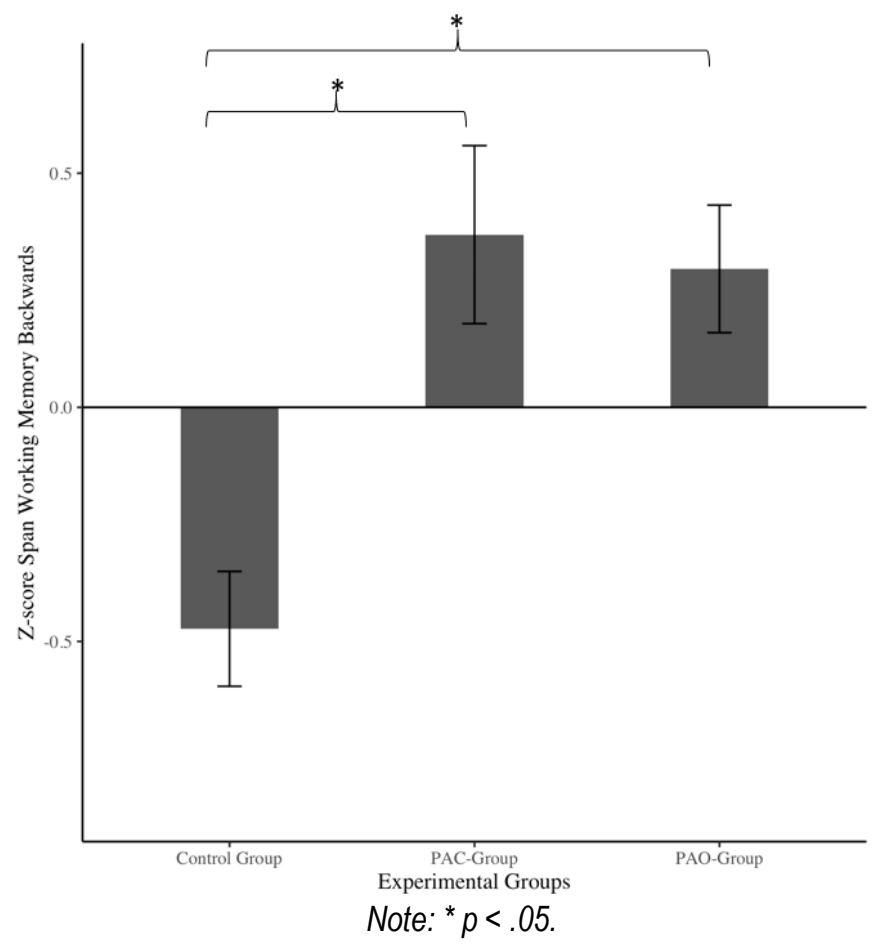

Figure 1. Z-scores value0 on Digit Span Working-Memory test (Backwards) of the three Experimental groups. 
ANOVA analysis revealed the Physical Activity factor to be significant $\left(F(2,106)=9.57, \eta_{p}^{2}=0.15, p=\right.$ $.00001)$. The post-hoc analysis revealed better WM capacities for the PAO group compared to $C$ one ( $t$ $(106)=3.39, p=.003 ; M=0.29, S E=0.14$ VS. $M=-0.47, S E=0.12$ ) as well as better WM capacities for the PAC group than the $\mathrm{C}$ one $(\mathrm{t}(106)=3.80, p=.0007 ; \mathrm{M}=0.37, \mathrm{SE}=0.19 \mathrm{VS} . \mathrm{M}=-0.47, \mathrm{SE}=0.12)$. No difference between PAO and PAC ( $\mathrm{t}(106)=0.87, p=1)$ was found. No difference between the two genders $\left(F(1,106)=1.51, \eta_{p}^{2}=0.01, p=.17\right.$; Females $M=-0.03$, SE $=0.10$ VS. Males $M=0.16$, $S E=$ $0.17)$ emerged.

\section{DISCUSSION}

Physical and sports activities are significant for the psycho-physical development of each individual (Elward \& Larson, 1992; Harridge \& Lazarus, 2017; Paluska \& Schwenk, 2000; WHO, 2018).

In particular, for what concerns the impact of PA on the cognitive domain, the body of research aimed at understanding such a relation has increased in the last decades (Biddle \& Asare, 2011; Biddle, Stuart, Ciaccioni, Thomas \& Vergeer, 2019; de Greef, Bosker, Oosterlaan, Visscher, Hartman, 2019; Donnelly, Hillman, Castelli, Etnier, Lee, Tomporowski, Lambourne, \& Szabo-Reed, 2016); however, such research displays controversial results, mainly when PA is analysed considering the difference between open/closed-skill activities.

One of the reasons for such unstable results might be related to the difficulty of individuating and analysing the cognitive functions modulated by PA systematically. Moreover, methodological heterogeneity is as high as to negatively impact the work of data summarizing (Russo \& Ottoboni, 2019; Gu et al., 2019).

To make a step forwards in the direction of systematically studying the modulating effect of the PA on cognitive functions, this research concentrated on a specific aspect of verbal working memory (the ability to recall backwards a series of digits). The task was adopted as it specifically taxes the short-term auditory memory, it is less dependent on attention fluctuations, and it enrols more both control functions and visualspatial skills (St Clair-Thompson \& Allen, 2013; Baddeley, 2012; Hale et al., 2002; Reynolds, 1997; Yang et., 2015). Given the nature of open skill sports, where an essential ability is to manipulate information while in temporary storage (Pesce et al., 2009), BSD was assumed to represent the best choice for disentangling the effects of open vs closed skill activities. Moreover, we controlled for the impact of Gender on WM. Results showed no effect of Gender on WM abilities corroborating our hypothesis (Gugliotta, 2009; Hill, Laird \& Robinson, 2013, Hyde, 2016).

However, a significant effect of the physical/sport activity emerged on WM. Beyond the sport categorization, pre-adolescents regularly practising a physical/sport activity showed better WM abilities than the control group composed of less active pre-adolescents.

This result is in line with other studies showing a general increase of cognitive capacities in both children and adults practising PA (de Greef et al., 2019; Rathore \& Lom, 2018), since PA enhances cardiovascular activity, increasing the cerebral oxygenation, in turns (Mücke, Ludyga, Colledge \& Gerber, 2018; Nettlefold, McKay, McGuire, Warburton, Bredin \& Naylor, 2012; Nettlefold, McKay, Naylor, Bredin \& Warburton, 2012).

Moreover, the same result might also be dependent on another crucial aspect that features the beginning of any structured PA. Due to their beginners' freshness, trainers must spend a reasonable amount of time 
providing beginners with several instructions about the aspects that compose the exercises. From the instructions, beginners start learning how to reach the best motor coordination, keep the best motor actions in response to conditions volatility, and respect the rules underpinning any sport or PA (Singer 1980; Wulf, Shea \& Lewthwaite, 2010). Usually, such attempts are carried by keeping high psychophysiological arousal and the personal interest necessary to learn (Beuter \& Duda, 1985; Beuter, Duda \& Widule, 1989; Bailey, Cope \& Pearce, 2013). For instance, in both PAO and PAC activities, trainers use competitive relay races. In response to all these simulations, beginners are required to code, remember, and recall each step composing the exercise, including the way to perform it. In any new activity, beginners are prompted to employ a large amount of cognitive effort and several times per week, which may not tax the sedentary peers in the same manner. As it emerged in studying the effect that music exerts on the cognitive abilities (Roden, Grube, Bongard \& Kreutz, 2014), the supplementary music exercises modify the brain structure, frontal region in particular, as they involve cognitive requests (Black, Isaacs, Anderson, Alcantara, \& Greenough, 1990; Blakemore, 2003; Chaddock, Pontifex, Hillman \& Kramer, 2011; Castelli \& Buck, 2005). In keeping with that, we can assume that, as PA and music both share cognitive demands. However, they can be supposed to differ in the volume of oxygen involved, our results would have needed to be controlled for the amount of oxygen involved and on more cognitive tests than what was done in this study (for example, motor WM; Rumiati \& Tessari 2002; Tessari \& Rumiati, 2002). By involving mental processes reversing digit sequences stored in temporal storages, DSB was assumed to tax preferably open skill athletes, as the two should have relied on visuospatial and executive abilities.

\section{Limitations}

As already suggested before, in possible future investigations, the use of instruments for the accurate measurement of PA levels such as oxygen meters, accelerometers or an ad-hoc made questionnaire (e.g., $P A Q-C)$ should be considered. Despite the respective qualitative and quantitative limitations, the instruments would have enriched the study by supporting the precise control of the young participants' activities in all their life contexts, such as playing with friends in a park.

\section{CONCLUSION}

The present study supports the beneficial effect of physical and sports activities on cognitive functions in the developmental age. In particular, this investigation enriches the body of research reporting the positive impact of PA on cognitive ability, by focusing mainly on the working memory. The present study presents practical outcomes, too. Results can be useful for teachers, and they support the promotion of supplementary activities for the enhancements of the cognitive functions. Moreover, as our results involved WM abilities, they are significant for the school contexts because they are strongly involved in the learning process and are based on complex cognitive functions, such as arithmetic, spoken, and written language, reasoning problem-solving. In this light, as many international agencies frequently suggest, the systematized planning of supplementary PA might represent a critical point in the future national and international health plans (D'Elia, Tortella, Sannicandro \& D'Isanto, 2020).

\section{AUTHORS CONTRIBUTION}

$R G$ and $O G$ contributed equally to the manuscript. RG collected the data, analysed the data, drafted and finalized the manuscript. OG analysed the data, drafted and finalized the manuscript. TA supervised the project and finalized the manuscript. CA collected the data and approved the manuscript. 


\section{REFERENCES}

Altavilla, G., D'Elia, F., Raiola, G. (2018) A brief review of the effects of physical activity in subjects with cardiovascular disease: An interpretative key. Sport Mont, 16 (3), pp. 103-106. https://doi.org/10.26773/smi.181018

Baddeley, A. (2012). Working Memory: Theories, Models, and Controversies. Annual Review of Psychology, 63(1), 1-29. https://doi.org/10.1146/annurev-psych-120710-100422

Beuter, A., \& Duda, J. L. (1985). Analysis of the arousal/motor performance relationship in children using movement kinematics. Journal of Sport and Exercise Psychology, 7(3), 229-243. https://doi.org/10.1123/jsp.7.3.229

Beuter, A., Duda, J. L., \& Widule, C. J. (1989). The effect of arousal on joint kinematics and kinetics in children. Research Quarterly for Exercise and Sport, 60(2), 109-116. https://doi.org/10.1080/02701367.1989.10607425

Biddle, S. J. H., \& Asare, M. (2011). Physical activity and mental health in children and adolescents: A review of reviews. British Journal of Sports Medicine, 45(11), 886-895. https://doi.org/10.1136/bjsports-2011-090185

Biddle, Stuart J.H., Ciaccioni, S., Thomas, G., \& Vergeer, I. (2019). Physical activity and mental health in children and adolescents: An updated review of reviews and an analysis of causality. Psychology of Sport and Exercise, 42, 146-155. https://doi.org/10.1016/j.psychsport.2018.08.011

Black, J. E., Isaacs, K. R., Anderson, B. J., Alcantara, A. A., \& Greenough, W. T. (1990). Learning causes synaptogenesis, whereas motor activity causes angiogenesis, in cerebellar cortex of adult rats. Proceedings of the National Academy of Sciences, 87(14), 5568-5572. https://doi.org/10.1073/pnas.87.14.5568

Blakemore, C. L. (2003). Movement is Essential to Learning. Journal of Physical Education, Recreation \& Dance, 74(9), 22-25. https://doi.org/10.1080/07303084.2003.10608514

Caspersen, C. J., Powell, K. E., \& Christenson, G. M. (1985). Physical activity, exercise, and physical fitness: Definitions and distinctions for health-related research. Public Health Rep, 100(2), 126-131.

Chaddock, L., Pontifex, M. B., Hillman, C. H., \& Kramer, A. F. (2011). A Review of the Relation of Aerobic Fitness and Physical Activity to Brain Structure and Function in Children. Journal of the International Neuropsychological Society, 17(6), 975-985. https://doi.org/10.1017/S1355617711000567

Conway, A. R. A., Kane, M. J., \& Engle, R. W. (2003). Working memory capacity and its relation to general intelligence. Trends in Cognitive Sciences, 7(12), 547-552. https://doi.org/10.1016/j.tics.2003.10.005

Davis, C. L., Tomporowski, P. D., Boyle, C. A., Waller, J. L., Miller, P. H., Naglieri, J. A., \& Gregoski, M. (2007). Effects of Aerobic Exercise on Overweight Children's Cognitive Functioning. Research Quarterly for Exercise and Sport, 78(5), 510-519. https://doi.org/10.1080/02701367.2007.10599450

de Bruijn, A. G. M., Kostons, D. D. N. M., van der Fels, I. M. J., Visscher, C., Oosterlaan, J., Hartman, E., \& Bosker, R. J. (2019). Importance of aerobic fitness and fundamental motor skills for academic achievement. Psychology of Sport and Exercise, 43, 200-209. https://doi.org/10.1016/.psychsport.2019.02.011

de Greeff, J. W., Bosker, R. J., Oosterlaan, J., Visscher, C., \& Hartman, E. (2018). Effects of physical activity on executive functions, attention and academic performance in pre-adolescent children: A meta-analysis. Journal of Science and Medicine in Sport, 21(5), 501-507. https://doi.org/10.1016/j.jsams.2017.09.595

D'Elia, F., Tortella, P., Sannicandro, I., \& D'Isanto, T. (2020). Design and teaching of physical education for children and youth. Journal of Human Sport and Exercise, 15(4proc), S1527-S1533. https://doi.org/10.14198/ihse.2020.15.Proc4.48 
Donnelly, J. E., Hillman, C. H., Castelli, D., Etnier, J. L., Lee, S., Tomporowski, P., Lambourne, K., \& Szabo-Reed, A. N. (2016). Physical Activity, Fitness, Cognitive Function, and Academic Achievement in Children: A Systematic Review. Medicine \& Science in Sports \& Exercise, 48(6), 1197-1222. https://doi.org/10.1249/MSS.0000000000000901

Elward, K., \& Larson, E. B. (1992). Benefits of Exercise for Older Adults: A Review of Existing Evidence and Current Recommendations for the General Population. Health Promotion and Disease Prevention, 8(1), 35-50. https://doi.org/10.1016/S0749-0690(18)30496-8

Fairclough, S. J., Beighle, A., Erwin, H., \& Ridgers, N. D. (2012). School day segmented physical activity patterns of high and low active children. BMC Public Health, 12(1), 406. https://doi.org/10.1186/14712458-12-406

Furley, P. A., \& Memmert, D. (2010). The role of working memory in sport. International Review of Sport and Exercise Psychology, 3(2), 171-194. https://doi.org/10.1080/1750984X.2010.526238

Gu, Q., Zou, L., Loprinzi, P. D., Quan, M., \& Huang, T. (2019a). Effects of Open Versus Closed Skill Exercise on Cognitive Function: A Systematic Review. Frontiers in Psychology, 10, 1707. https://doi.org/10.3389/fpsyg.2019.01707

Gugliotta, M. (2009). BVN 12-18: Batteria di valutazione neuropsicologia per l'adolescenza. Edizioni Erickson.

Hale, J. B., Hoeppner, J.-A. B., \& Fiorello, C. A. (2002). Analyzing Digit Span Components for Assessment of Attention Processes. Journal of Psychoeducational Assessment, 20(2), 128-143. https://doi.org/10.1177/073428290202000202

Harridge, S. D. R., \& Lazarus, N. R. (2017). Physical Activity, Aging, and Physiological Function. Physiology, 32(2), 152-161. https://doi.org/10.1152/physiol.00029.2016

Hill, A. C., Laird, A. R., \& Robinson, J. L. (2014). Gender differences in working memory networks: A BrainMap meta-analysis. Biological Psychology, 102, 18-29. https://doi.org/10.1016/i.biopsycho.2014.06.008

Hillman, C. H., Castelli, D. M., \& Buck, S. M. (2005). Aerobic Fitness and Neurocognitive Function in Healthy Pre-adolescent Children: Medicine \& Science in Sports \& Exercise, 37(11), 1967-1974. https://doi.org/10.1249/01.mss.0000176680.79702.ce

Hillman, C. H., Kamijo, K., \& Scudder, M. (2011). A review of chronic and acute physical activity participation on neuroelectric measures of brain health and cognition during childhood. Preventive Medicine, 52, S21-S28. https://doi.org/10.1016/i.ypmed.2011.01.024

Hsieh, S.-S., Fung, D., Tsai, H., Chang, Y.-K., Huang, C.-J., \& Hung, T.-M. (2018). Differences in working memory as a function of physical activity in children. Neuropsychology, 32(7), 797-808. https://doi.org/10.1037/neu0000473

Hyde, J. S. (2016). Sex and cognition: Gender and cognitive functions. Current Opinion in Neurobiology, 38, 53-56. https://doi.org/10.1016/i.conb.2016.02.007

Kamijo, K., Pontifex, M. B., O'Leary, K. C., Scudder, M. R., Wu, C.-T., Castelli, D. M., \& Hillman, C. H. (2011). The effects of an afterschool physical activity program on working memory in pre-adolescent children: Fitness and working memory in children. Developmental Science, 14(5), 1046-1058. https://doi.org/10.1111/j.1467-7687.2011.01054.x

Keeley, T. J. H., \& Fox, K. R. (2009). The impact of physical activity and fitness on academic achievement and cognitive performance in children. International Review of Sport and Exercise Psychology, 2(2), 198-214. https://doi.org/10.1080/17509840903233822

Kwon, H., Reiss, A. L., \& Menon, V. (2002). Neural basis of protracted developmental changes in visuospatial working memory. Proceedings of the National Academy of Sciences, 99(20), 13336-13341. https://doi.org/10.1073/pnas.162486399 
Marsico, E., Isanto, T. D., Raiola, G., \& Cassese, F. P. (2019). Università degli Studi Niccolò Cusano 2 University of Salerno, Italy Original scientific paper. 13, 64-73.

Milner, B. (1971). Interhemispheric differences in the localization of psychological processes in man. British Medical Bulletin, 27(3), 272-277. https://doi.org/10.1093/oxfordjournals.bmb.a070866

Mora-Gonzalez, J., Esteban-Cornejo, I., Cadenas-Sanchez, C., Migueles, J. H., Rodriguez-Ayllon, M., Molina-García, P., Hillman, C. H., Catena, A., Pontifex, M. B., \& Ortega, F. B. (2019). Fitness, physical activity, working memory, and neuroelectric activity in children with overweight/obesity. Scandinavian Journal of Medicine \& Science in Sports, 29(9), 1352-1363. https://doi.org/10.1111/sms.13456

Mücke, M., Ludyga, S., Colledge, F., \& Gerber, M. (2018). Influence of Regular Physical Activity and Fitness on Stress Reactivity as Measured with the Trier Social Stress Test Protocol: A Systematic Review. Sports Medicine, 48(11), 2607-2622. https://doi.org/10.1007/s40279-018-0979-0

Nettlefold, L., McKay, H., McGuire, A., Warburton, D., Bredin, S., \& Naylor, P. (2012). Action Schools! BC: a whole-school physical activity model to increase children's physical activity. Journal of Science and Medicine in Sport, 15, S114. https://doi.org/10.1016/i.jsams.2012.11.278

Nettlefold, Lindsay, McKay, H. A., Naylor, P.-J., Bredin, S. S. D., \& Warburton, D. E. R. (2012). The Relationship Between Objectively Measured Physical Activity, Sedentary Time, and Vascular Health in Children. American Journal of Hypertension, 25(8), 914-919. https://doi.org/10.1038/ajh.2012.68

O'Brien, J., Ottoboni, G., Tessari, A. et al. Multisensory Perception, Verbal, Visuo-spatial and Motor Working Memory Modulation After a Single Open- or Closed-Skill Exercise Session in Children. J Cogn Enhanc (2020). https://doi.org/10.1007/s41465-020-00189-x

O'Brien, J., Ottoboni, G., Tessari, A., \& Setti, A. (2017). One bout of open skill exercise improves crossmodal perception and immediate memory in healthy older adults who habitually exercise. PloS one, 12(6), e0178739. https://doi.org/10.1371/journal.pone.0178739

Paluska, S. A., \& Schwenk, T. L. (2000). Physical Activity and Mental Health. Sports Med, 14. https://doi.org/10.2165/00007256-200029030-00003

Ottoboni, G., Russo, G., \& Tessari, A. (2015). What boxing-related stimuli reveal about response behaviour. Journal of Sports Sciences, 33(10), 1019-1027. https://doi.org/10.1080/02640414.2014.977939

Panza, G. A., Taylor, B. A., MacDonald, H. V., Johnson, B. T., Zaleski, A. L., Livingston, J., Thompson, P. D., \& Pescatello, L. S. (2018). Can Exercise Improve Cognitive Symptoms of Alzheimer's Disease? Journal of the American Geriatrics Society, 66(3), 487-495. https://doi.org/10.1111/jgs.15241

Pesce, C., Crova, C., Cereatti, L., Casella, R., \& Bellucci, M. (2009). Physical activity and mental performance in pre-adolescents: Effects of acute exercise on free-recall memory. Mental Health and Physical Activity, 2(1), 16-22. https://doi.org/10.1016/..mhpa.2009.02.001

Qin, F., Song, Y., Nassis, G. P., Zhao, L., Cui, S., Lai, L., Wu, Z., Xu, M., Qu, C., \& Dong, Y. (2020). Prevalence of Insufficient Physical Activity, Sedentary Screen Time and Emotional Well-Being During the Early Days of the 2019 Novel Coronavirus (COVID-19) Outbreak in China: A National CrossSectional Study. https://doi.org/10.2139/ssrn.3566176

Raiola, G. (2015). Sport skills and mental health. Journal of Human Sport and Exercise, 10(Proc1), S369S376. https://doi.org/10.14198//hse.2015.10.Proc1.27

Raiola, G., Aliberti, S., Esposito, G., Altavilla, G., D'Isanto, T., \& D'Elia, F. (2020). How has the Practice of Physical Activity Changed During the COVID-19 Quarantine? A Preliminary Survey. Teoriâ Ta Metodika Fizičnogo Vihovannâ, 20(4), 242-247. https://doi.org/10.17309/tmfv.2020.4.07 
Rathore, A., \& Lom, B. (2017). The effects of chronic and acute physical activity on working memory performance in healthy participants: A systematic review with meta-analysis of randomized controlled trials. Systematic Reviews, 6(1), 124. https://doi.org/10.1186/s13643-017-0514-7

Reynolds, C. R. (1997). Forward and backward memory span should not be combined for clinical analysis. Archives of Clinical Neuropsychology, 12(1), 29-40. https://doi.org/10.1016/S0887$\underline{6177(96) 00015-7}$

Roden, I., Grube, D., Bongard, S., \& Kreutz, G. (2014). Does music training enhance working memory performance? Findings from a quasi-experimental longitudinal study. Psychology of Music, 42(2), 284-298. https://doi.org/10.1177/0305735612471239

RStudio Team(2015): Integrated development for R. RStudio, Inc., Boston, MA URL Http://Www. Rstudio. Com, 42, 14.

Rumiati, R., \& Tessari, A. (2002). Imitation of novel and well-known actions. Experimental Brain Research, 142(3), 425-433. https://doi.org/10.1007/s00221-001-0956-x

Russo, G., Castagnoli, M.S., Babini, A., \& Ceciliani, A. (2020). A post COVID lockdown pilot study on the effect of physical activity intensity on cognitive functions of children aged 6-8 years old. Journal of Human Sport and Exercise, 15(4proc), S1140-S1151. https://doi.org/10.14198/ihse.2020.15.Proc4.15

Russo, G., Nigro, F., Raiola, G., \& Ceciliani, A. (2019). The role of the extra physical activity on memory storage and psychosocial features. Journal of Human Sport and Exercise, 14(Proc4), S948-S956. https://doi.org/10.14198/ihse.2019.14.Proc4.57

Russo, G., Nigro, F., Raiola, G., \& Ceciliani, A. (2019). Self-esteem in physically active middle school students. Journal of Physical Education and Sport, 19(5), 1984-1988. https://doi.org/10.7752/jpes.2019.s5295

Russo, G., \& Ottoboni, G. (2019). The perceptual - Cognitive skills of combat sports athletes: A systematic review. Psychology of Sport and Exercise, 44, 60-78. https://doi.org/10.1016/.psychsport.2019.05.004

Schmidt, R. A., \& Wrisberg, C. A. (2008). Motor learning and performance: A situation-based learning approach. Human kinetics.

Scudder, M. R., Drollette, E. S., Szabo-Reed, A. N., Lambourne, K., Fenton, C. I., Donnelly, J. E., \& Hillman, C. H. (2016). Tracking the relationship between children's aerobic fitness and cognitive control. Health Psychology, 35(9), 967-978. https://doi.org/10.1037/hea0000343

Sibley, B. A., \& Etnier, J. L. (2003). The Relationship between Physical Activity and Cognition in Children: A Meta-Analysis. Pediatric Exercise Science, 15(3), 243-256. https://doi.org/10.1123/pes.15.3.243

Singer, R. N. (1980). Motor learning and human performance: An application to motor skills and movement behaviors ( $3 \mathrm{~d}$ ed). MacMillan.

Sjöwall, D., Hertz, M., \& Klingberg, T. (2017). No Long-Term Effect of Physical Activity Intervention on Working Memory or Arithmetic in Preadolescents. Frontiers in Psychology, 8, 1342. https://doi.org/10.3389/fpsyg.2017.01342

St Clair-Thompson, H. L., \& Allen, R. J. (2013). Are forward and backward recall the same? A dual-task study of digit recall. Memory \& Cognition, 41(4), 519-532. https://doi.org/10.3758/s13421-012-0277$\underline{2}$

Tessari, A., Ottoboni, G., \& Nicoletti, R. (2013). The effect of expertise on the processes underlying movement and body coding: A study on expert volleyball players. Giornale italiano di psicologia, 40(3), 647-656.

Tessari, A., \& Rumiati, R. I. (2002). Motor distal component and pragmatic representation of objects. Cognitive Brain Research, 14(2), 218-227. https://doi.org/10.1016/S0926-6410(02)00133-7 
Tomporowski, P. D. (2003). Cognitive and Behavioral Responses to Acute Exercise in Youths: A Review. Pediatric Exercise Science, 15(4), 348-359. https://doi.org/10.1123/pes.15.4.348

Tomporowski, P. D., Lambourne, K., \& Okumura, M. S. (2011). Physical activity interventions and children's mental function: An introduction and overview. Preventive Medicine, 52, S3-S9. https://doi.org/10.1016/i.ypmed.2011.01.028

van der Niet, A. G., Hartman, E., Smith, J., \& Visscher, C. (2014). Modeling relationships between physical fitness, executive functioning, and academic achievement in primary school children. Psychology of Sport and Exercise, 15(4), 319-325. https://doi.org/10.1016/i.psychsport.2014.02.010 van der Niet, A. G., Smith, J., Oosterlaan, J., Scherder, E. J. A., Hartman, E., \& Visscher, C. (2016). Effects of a Cognitively Demanding Aerobic Intervention During Recess on Children's Physical Fitness and Executive Functioning. Pediatric Exercise Science, 28(1), 64-70. https://doi.org/10.1123/pes.2015-0084

Wang, C.-H., Chang, C.-C., Liang, Y.-M., Shih, C.-M., Chiu, W.-S., Tseng, P., Hung, D. L., Tzeng, O. J. L., Muggleton, N. G., \& Juan, C.-H. (2013). Open vs. Closed Skill Sports and the Modulation of Inhibitory Control. PLoS ONE, 8(2), e55773. https://doi.org/10.1371/journal.pone.0055773

World Health Organization. (2020). Mental health and psychosocial considerations during the COVID-19 outbreak, 18 March 2020 (No. WHO/2019-nCoV/MentalHealth/2020.1). World Health Organization. WHO (2018). Physical activity. https://www.who.int/news-room/fact-sheets/detail/physical-activity Wulf, G., Shea, C., \& Lewthwaite, R. (2010). Motor skill learning and performance: A review of influential factors. Medical Education, 44(1), 75-84. https://doi.org/10.1111//.1365-2923.2009.03421.x

Yang, Z., Jutagir, D. R., Koyama, M. S., Craddock, R. C., Yan, C.-G., Shehzad, Z., Castellanos, F. X., Di Martino, A., \& Milham, M. P. (2015). Intrinsic brain indices of verbal working memory capacity in children and adolescents. Developmental Cognitive Neuroscience, 15, 67-82. https://doi.org/10.1016/j.den.2015.07.007

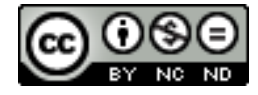

This work is licensed under a Attribution-NonCommercial-NoDerivatives 4.0 International (CC BY-NC-ND 4.0). 